Sharif University of Technology
Scientia Iranica
SCIENTIA
IRAN ICAA
http://scientiairanica.sharif.edu

\title{
The shear and flexural behavior of cold-formed steel composite I and U beams
}

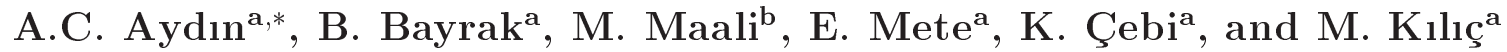 \\ a. Department of Civil Engineering, Engineering Faculty, Atatürk University, Erzurum, 25030, Turkey. \\ b. Department of Civil Engineering, Engineering and Architecture Faculty, Erzurum Technical University, Erzurum, Turkey. \\ Received 12 November 2020; received in revised form 25 December 2020; accepted 1 February 2021
}

\section{KEYWORDS \\ Cold-formed steel; \\ Polypropylene; \\ Flexural and shear \\ behavior; \\ Waste; \\ Plastic waste.}

\begin{abstract}
Recycling and re-usability of waste materials are of great importance in terms of ecological order. Furthermore, cold-formed steel has recently drawn considerable attention. The objective of the present study was to investigate the bending and shear behavior of the composite formed by pouring waste polymer into the cold-formed I and U profile melds after homogenous pulping. The best results for shear and bending strengths were obtained using melted polypropylene (PP). The enhanced adherence between the steel and molted PP increased both shear and bending capacity. Moreover, it was reinforced by Carbon Fiber Reinforced Polymer (CFRP) and Glass Fiber Reinforced Polymer (GFRP) bars to increase the bending and shear behavior of I and U profiles filled with melted waste polymer. Changing the cross-sectional area in I and U beams under the bending moment had a considerable effect on the load at yielding, ultimate strength, displacement values corresponding to these loads, ductility, and energy dissipation capacity. Addition of CFRP to I beams could also significantly increase displacement capacity in free end regions under the shear force. Addition of GFRP bars, rather than CFRP bars, with a higher elongation capacity in I and U beams caused ductile behavior.
\end{abstract}

(C) 2021 Sharif University of Technology. All rights reserved.

\section{Introduction}

Studies and research on cold-formed steel elements began in the 1930s. In the 1950s, permanent, functional, and durable structures were first built using coldformed steel systems, primarily in the United States and Canada. Such studies have been conducted with the aim of cheap and efficient steel production, thanks to the Bessemer Process (easy to use and low cost) found by Henry Bessemer in the 19th century. In the past few decades, cold-formed steel sections have become increasingly popular for residential, commercial, and industrial buildings due to their convenience

*. Corresponding author. Tel.: +90442 2314781 E-mail address: acaydin@atauni.edu.tr (A.C. Aydın)

doi: $10.24200 /$ sci. 2021.57157 .5092 in erection, transportation, and assembling. However, both stiffness and strength of the cold-formed steel materials deteriorate at high temperatures, which causes great concerns in their fire safety in structural applications [1]. Cold-formed steels are increasingly used in the construction industry as efforts at introduction of a greater degree of pre-fabrication and industrialized processes continue. According to the literature, an increasing number of studies have addressed the usage of cold-formed steel construction techniques [2]. Use of cold-formed steel for structural members in a lightsteel structure has aroused considerable interest due to its light weight, high strength, high rigidity, and easy processing. Cold-formed steel can exhibit good mechanical properties with a reasonable section shape. Cold working results in an increase in the strength and a decrease in the ductility; therefore, the mechanical properties of cold-formed steel are different from those 
of the hot-rolled steel [3]. Another advantage of using cold-formed steel is its ability to improve the technology of manufacturing and corrosion protection which, in turn, leads to the increased competitiveness of the resulting product as well as new applications [4]. The construction technology plays a significant role in today's societies. In addition, green manufacturing and industrial ecology have gained significance in the recent years. As an innovative perspective, designing cold-formed steel profiles using waste materials, as the filler materials, cannot only enhance some mechanical properties but also regain waste materials for a green world.

Nowadays, the application of waste materials to reduce the use of natural resources has gained greater significance all over the world. With the increasing trend of industrialization and fast-paced technology, environmental pollution has exacerbated the problem. Keeping the amount of pollution to its minimum to take control over the increasing environmental pollution is a critical issue both for the public health and the future of the world [5,6]. Given the harmful effects of wastes that threaten the ecological balance and human health, attempts should be made to solve such ecological problems. Polymer-generated wastes are gradually accumulating in the environment, and the reduction of such wastes due to their high resistance has almost failed. According to estimates, $60 \%$ of plastic wastes from total production equal approximately 200 million tons per year $[7,8]$. Waste materials management should be taken into account to reuse the wastes as raw materials. In this respect, a number of studies on recycling the polymer wastes have been conducted in the current literature. However, no detailed study on using these wastes in profiles as the raw materials has been found. Today, major, yet sometimes uncalled-for, destruction and excessive exploitation of natural resources is among the problems involving the ecological order and balance. As a result of depletion of the natural resources, a number of irreversible problems have arisen in the long term [9]. To solve these problems, already existing wastes must be inspected, transformed, and made available as raw materials without harming natural resources. The inspection of wastes is of significance in terms of protecting natural resources that are not renewed, recycling unused wastes, preventing environmental pollution, protecting energy, and making energy reusable in production [10]. Although very important studies have been carried out under the headings of mild steel and waste polymer, there are few research pieces in the literature that target these two materials together.

Fiber Reinforced Polymer (FRP) bars were first used in beam elements about 20 years ago. However, during the first years of application, FPR was more expensive than steel bars. However, the cost of
FRP materials, compared to the steel ones, has been continuously decreasing owing to the lower costs of transportation and handling as well as their lighter weights $[11,12]$. Owing to their advantages, FRP bars have found their way into numerous construction elements such as beams, one-way and two-way slabs, and, more recently, columns [12-16]. A few techniques are available for strengthening or retrofitting structures. These techniques use different materials such as steel, concrete, and shape memory alloys used in different methods [17-19]. FRP bars enjoy other advantages such as easy applications in buildings, maintenancefree, high load bearing and bending capacities, good ductility and durability, light weight, and high resistance to corrosion [20-23]. Nowadays, FRP is one of the common methods for strengthening steel and concrete structures [24,25]. Use of Glass Fiber Reinforced Polymer (GFRP) bars as a viable alternative reinforcing material has grown to obviate corrosion issues while providing an acceptable level of performance [26]. Resistant to high-tension stress [27], Carbon Fiber Reinforced Polymer (CFRP) is utilized to increase the capacity of both simply-wrapped steel and concretesteel-I beams. FRP bars are widely used to retrofit a large number of steel structures [28]. However, Yu et al. [29] evaluated the behavior of hybrid FRP concrete steel characterized by a double-skin tubular-structural member. Concrete confinement using FRP composites has recently received great deal of attention [30]. Wang and Shao [31] reported that the longitudinal CFRP bars could en hance the stiffness of the circular concretefilled CFRP steel tubular specimens.

The objective of this study was to investigate the bending and shear behavior of $\mathrm{I}$ and $\mathrm{U}$ profiles made of mild steel filled with melted waste polymer. In addition, the effect of strength was investigated by adding CFRP and GFRP rods to polymer and I and U profiles. Maali et al. [32] and Kılıç et al. [33] conducted preliminary experiments. This experimental program in this study was created according to the results obtained by Maali et al. [32] and Kılıç et al. [33]. The study program is divided into two groups of $\mathrm{I}$ and $\mathrm{U}$ cross-sectional areas. Each group consists of hollow sections filled with melted polypropylene (PP), melted PP and CFRP rod reinforced, and melted PP and GFRP reinforced samples. However, four-point bending and overhanging tests were performed on each sample.

\section{Experimental program}

\subsection{Test specimens and materials}

IPE and UPE steel profiles are the European Standard I- and U-sections typically used for beams, columns, and cantilever structural members. While IPE is the short form for rod structural members or beams 


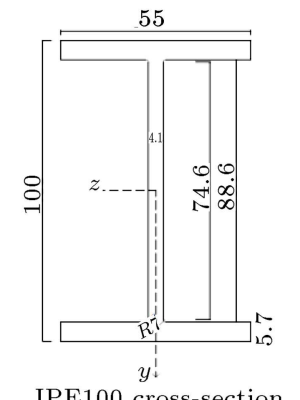

IPE100 cross-section

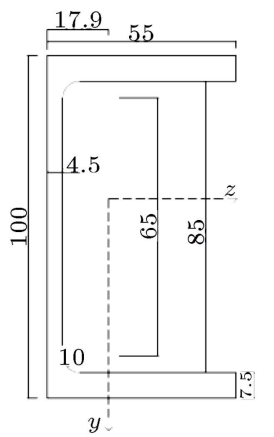

UPE 100 cross-section
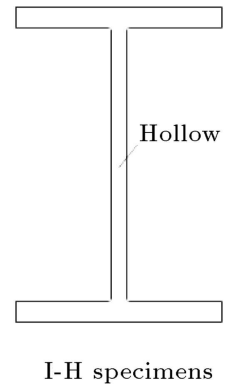
cross-section

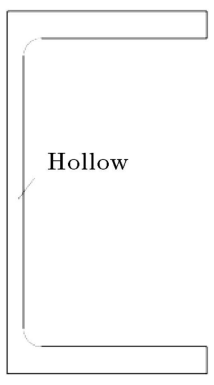

U-H specimens cross-section
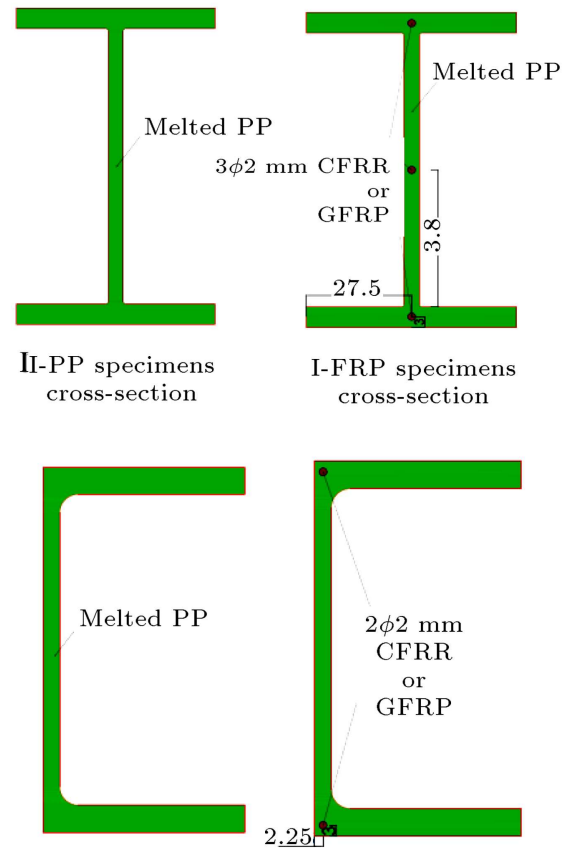

U-PP specimens cross-section

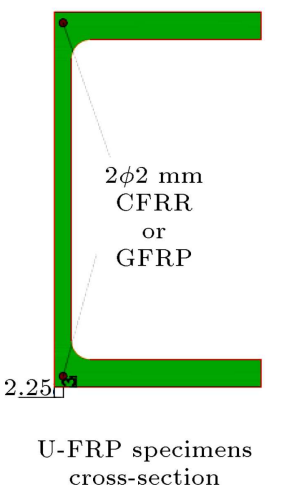

Figure 1. Cross-section of the tested specimens (all units are in $\mathrm{mm}$ ).

with parallel inner surface of flanges and dimensions according to EN 10365 [34], UPN is the short form for the standardized channel sections according to EN 10365 [34]. Stainless steel UPN profiles are used in all kinds of industrial applications, machinery, and equipment construction. In this study, the test specimens were manufactured by IPE100 and UPE100 coldformed steel profiles. The section properties of IPE100 and UPE100 are presented in Figure 1. Eight steel beams were manufactured to investigate the flexural and shear behavior. Steel beams with IPE and UPE sections were loaded from their mid-point and free-ends for flexural and shear tests with the monotonic point load that increased to the collapse point. This study considers two main experimental variables, namely IPE100 and UPE100. Each group is divided into four groups. In the first group, hollow I100 and U100 crosssectional specimens were produced as the reference samples. In the second group, samples filled with PP melted into the mixture were produced. They were produced by adding CFRP and GFRP bars into the melted PP in the third and fourth groups. Table 1 presents a summary of the properties of the tested specimens. The tested beams were then sorted into two groups of I and U based on their cross-section. Each group is itself divided into two categories based on the loading type, namely four-point bending (B) and overhanging (S). The second column related to the names of the specimen determines whether the inside of I or U profiles is hollow and what materials are used.
The length $(1500 \mathrm{~mm})$ and thickness $(1.2 \mathrm{~mm})$ of the tested specimens are kept constant for both I and U profiles.

Since it was predicted that the pulp obtained from finely ground raw PP would interact better with CFRP and GFRP bars, these bars, with diameters of $2 \mathrm{~mm}$, were then added to the I and $\mathrm{U}$ section profiles. When determining the diameters of the CFRP and GFRP bars, the most important criterion was chosen as the value smaller than the wall thickness of the I100 and U100 profiles. While three pieces of fiber bars with diameters of $2 \mathrm{~mm}$ were placed mainly in the middle and at the end of each I profile, two pieces of fiber bars with diameters of $2 \mathrm{~mm}$ were placed in each $\mathrm{U}$ profile. Table 2 shows the properties of PP and CFRP bars as well as GFRP bar that are used for the experimental tests. Due to its low density, high-tensile strength, high resistance to environmental and chemical materials, and corrosion resistance, melted $\mathrm{PP}$ is used in $\mathrm{I}$ and $\mathrm{U}$ profiles. Due to its lightness, the melted PP manages to increase the strength without adding excess weight to the element.

Hollow I and U profiles are filled with PP in two stages. In the first stage, I-PP and U-PP series were filled with $\mathrm{PP}$ up to the half-height of the profile and then, $\mathrm{PP}$ was melted at $200^{\circ} \mathrm{C}$. In the second stage, the other half of the profiles were filled with PP and melted. In the I-CFRP, I-GFRP and U-CFRP, U-GFRP series, FRP rods were placed in the profiles in the first stage. In the second stage, the profiles were filled and melted 
Table 1. Properties of the tested specimens.

\begin{tabular}{|c|c|c|c|}
\hline Cross-section & Specimen & Type of filler materials & Loading type \\
\hline \multirow{8}{*}{ 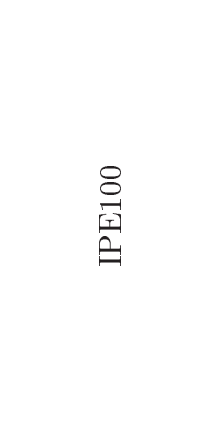 } & I-H-B & Hollow & \multirow{4}{*}{ Four point bending } \\
\hline & I-PP-B & Melted PP & \\
\hline & I-CFRP-B & Melted PP+CFRP & \\
\hline & I-GFRP-B & Melted PP+GFRP & \\
\hline & I-H-S & Hollow & \multirow{4}{*}{ Overhanging } \\
\hline & I-PP-S & Melted PP & \\
\hline & I-CFRP-S & Melted PP+CFRP & \\
\hline & I-GFRP-S & Melted PP+GFRP & \\
\hline \multirow{8}{*}{ 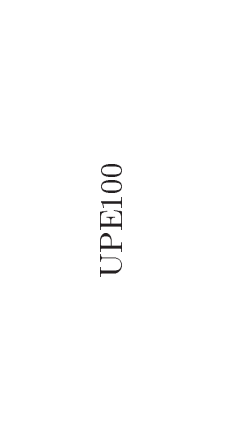 } & U-H-B & Hollow & \multirow{4}{*}{ Four point bending } \\
\hline & U-PP-B & Melted PP & \\
\hline & U-CFRP-B & Melted PP+CFRP & \\
\hline & U-GFRP-B & Melted PP+GFRP & \\
\hline & U-H-B & Hollow & \multirow{4}{*}{ Overhanging } \\
\hline & U-PP-B & Melted PP & \\
\hline & U-CFRP-B & Melted PP+CFRP & \\
\hline & U-GFRP-B & Melted PP+GFRP & \\
\hline
\end{tabular}

Table 2. Properties of Fiber Reinforced Polymer (FRP) bars.

\begin{tabular}{lccc}
\hline & CFRP & GFRP & PP \\
\hline Density $\left(\mathbf{k g} / \mathbf{m}^{\mathbf{3}}\right)$ & 1.5 & 2.4 & 0.92 \\
Tensile strength $(\mathbf{M P a})$ & $>2800$ & $>1600$ & 517 \\
Elastic modulus $(\mathbf{G P a})$ & $>165$ & $>53$ & 1.25 \\
Elongation (\%) & 1.7 & 3 & $>50$ \\
\end{tabular}

CFRP: Carbon Fiber Reinforced Polymer; GFRP: Glass Fiber Reinforced Polymer; PP: polypropylene.

with PP until halving. In the third stage, the other half of the profile was filled and melted with PP. Figure 2 shows the preparation stages of the samples.

\subsection{Testing procedures}

In the experimental program, the bending and shear behaviors of I and U profiles made of cold-formed steel were experimentally investigated. The mentioned behaviors of the models were then evaluated by fourpoint bending and overhanging tests. A universal testing system and a hydraulic jack with a maximum capacity of $1000 \mathrm{kN}$ were used during the test program. All specimens were tested in a displacement-control mode with the loading rate of $0.2 \mathrm{~mm} / \mathrm{min}$ until failure. The experimental setups for bending and shear are shown in Figure 3. The test setup for bending moment is shown in Figure 3(a). The deformation was measured by Linear Variable Differential Transformer (LVDT). In the four-point bending test, a total of three LVDTs were used, two of which were placed under the applied load points and one in the mid-point of the beam. Displacement values recorded from two LVDTs placed under the loads were used for control purposes. The bending behavior was evaluated by calculating the midpoint displacement values where maximum displacement would be expected. Midpoint displace- 


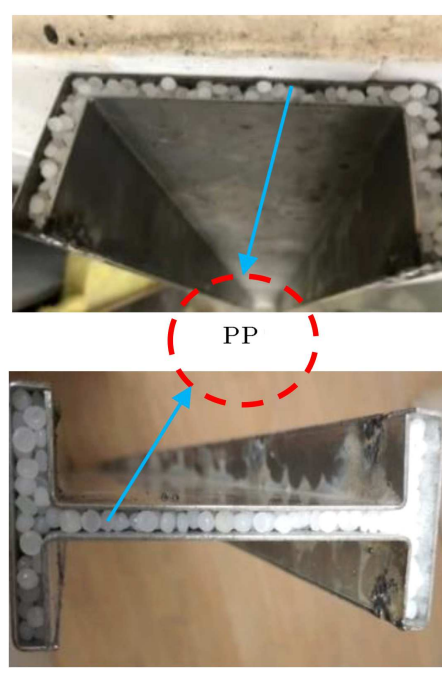

(a)

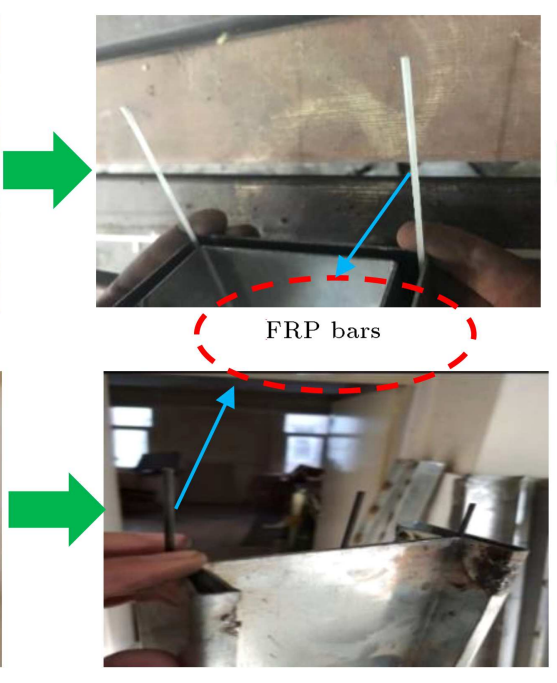

(b)

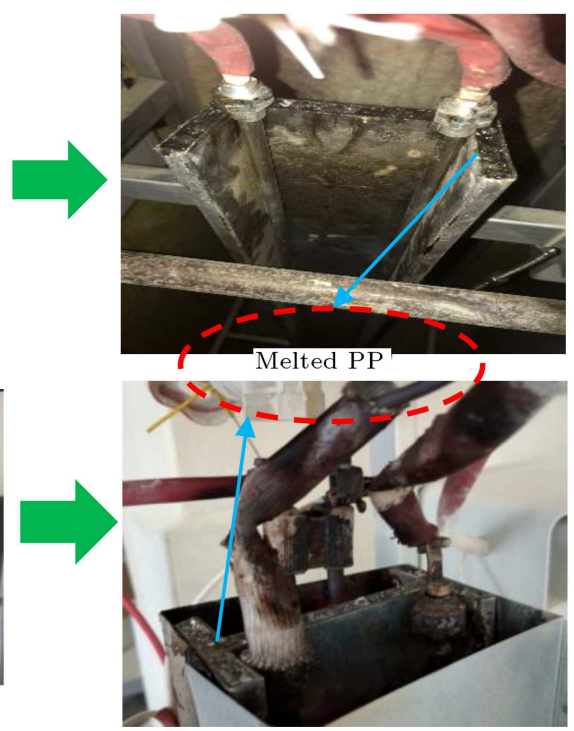

(c)

Figure 2. Specimen preparation: (a) Filling polypropylene (PP) into profiles, (b) placement of the Fiber Reinforced Polymer (FRP) bars, and (c) melting the PP.

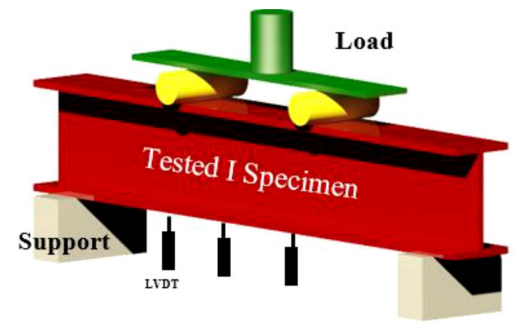

(a)
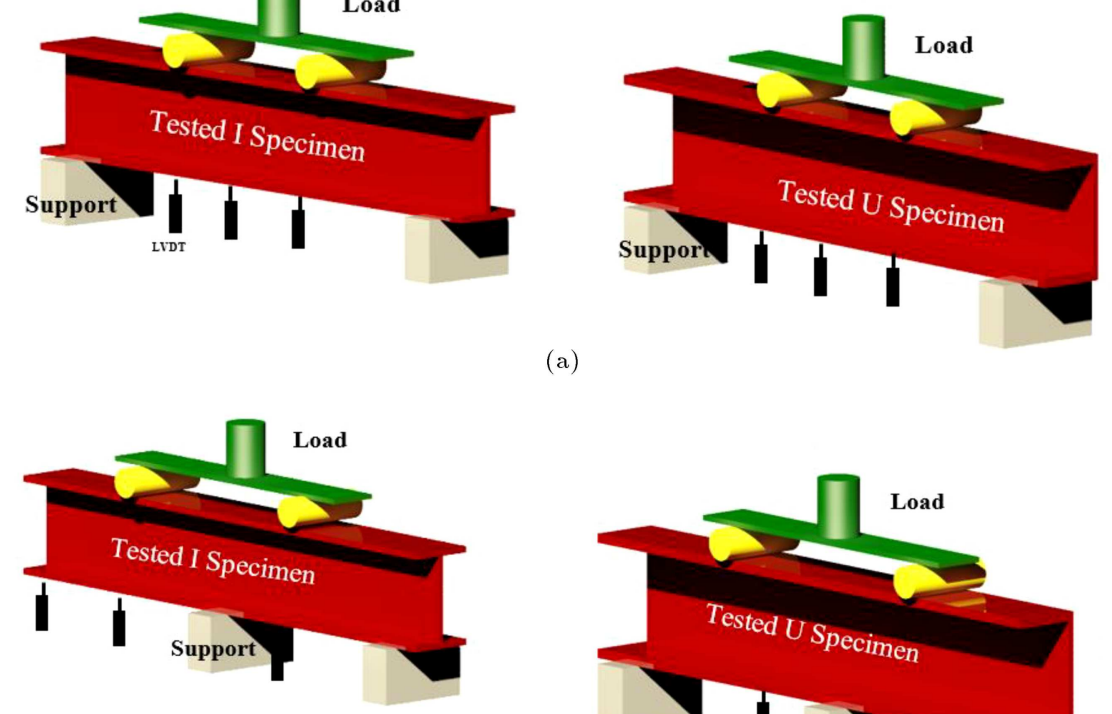

(b)

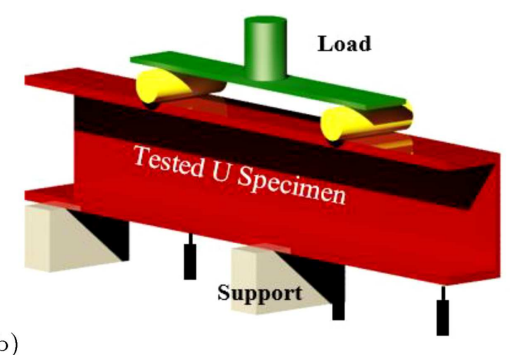

Figure 3. Test setup: (a) Bending and (b) overhanging. ment was also utilized to draw load-displacement plots. However, the horizontal and vertical strain gauges were placed at the center of the beam to measure the deformations caused by the increasing loads. For the overhanging tests, three LVDTs were used, as shown in Figure 3(b). Data of LVDTs were recorded and the load-displacement plots were drawn using a data logging system. For the overhanging setup (Figure 3(b)), the LVDTs were located at the load level in the free-end region at a point where shear force would be theoret- ically expected to be maximum. Therefore, free-end displacements were measured by LVDT placed in the free-end region instead of midpoint displacement. At the overhanging test, the midpoint displacements were neglected because they were less than their free-end counterparts. However, the mid-point displacement was not used in the load-displacement graphs. The free-end point of the test sample was placed to measure the deformations.

A unique experimental setup was designed by the 


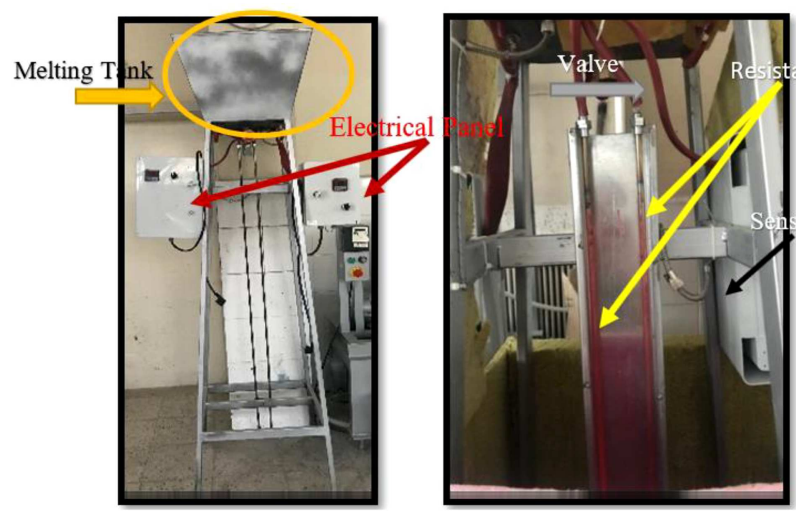

Figure 4. Melting test apparatus.

authors, specifically for an experimental study on the $\mathrm{PP}$ melting system. The melting device is introduced in Figure 4. The melting apparatus used for melting the waste polymers consists of DT 48 E digital single probe, contact, resistance, electrical panel, switch with on and off contact, and silicone cable. The degree of the melting device goes up to $300^{\circ}$. The temperature was monitored on a digital single probe and the waste polymer was removed at the melting temperature. The system continued its operation until homogeneous melting. In the scope of the experimental study, I and $\mathrm{U}$ profiles made of mild steel were connected to a device called melting apparatus. It was provided through a resistance system located around the heat of the melting device. This resistance system allows the mold to be heated at any point, thus reaching high temperature and easily melting the material inside. The system was checked before putting the waste PP melting apparatus inside the test samples. The molds were placed in the system and then, the test device began operating. The molds to be melted were placed in the system and the system began operating. Finely ground PP soon started to melt under the influence of heat (about 200 degrees). This device was designed in accordance with the size of the molds for easy placement of the molds and ease of material transfer. The system began to heat up in a short time span and the material inside the mold melted. As the material melted, it slid downwards and was compressed using an apparatus; then, the material was added to empty spots again. The system was then turned off and allowed to cool. The mold whose melting process was completed was taken out of the system.

\section{Test results}

This experimental study was evaluated in terms of both shear and bending behaviors. Upon evaluating the free-end displacements in terms of shear behavior, the midpoint displacements were observed in the bending behavior. The bending strength, shear strength, ductility, energy dissipation capacities, and strains were experimentally measured.

\subsection{Flexural behavior}

In this section, the bending resistance of I and $\mathrm{U}$ beams made of cold-formed steel is evaluated. A four-point bending test was employed to evaluate the flexural resistance of the beams. The experimental values for the tested beams are shown in Table 3. Experimental loads and displacements obtained from the four-point bending tests are presented in Table 3. In addition, ductility index values were calculated to compare the stiffness values for the beams. The ductility index is the ratio of the ultimate displacement $\left(\Delta_{0.85}\right)$ to displacement at yielding $\left(\Delta_{\text {ultimate }} / \Delta_{\text {yield }}\right)[35]$. Figure 5 shows the values of the ultimate load and yielding points of specimens. According to Table 3, the addition of melted PP to both I- and U-section beams made of cold-formed steel caused an increase in the yield and ultimate loads $\left(0.85 P_{\max }\right)$. The ultimate bending loads of the specimens were $186.3 \%$ and $12.3 \%$ higher than those of the reference specimen (compared to I-H-B and

Table 3. Experimental results of the bending test.

\begin{tabular}{lccccc}
\hline Specimen & $\begin{array}{c}\text { Load } \\
\text { at yield } \\
(\mathbf{k N})\end{array}$ & $\begin{array}{c}\text { Deflection } \\
\text { at yield load } \\
(\mathbf{m m})\end{array}$ & $\begin{array}{c}\text { Ultimate } \\
\text { load } \\
\mathbf{( k N )}\end{array}$ & $\begin{array}{c}\text { Ultimate } \\
\text { deflection } \\
(\mathbf{m m})\end{array}$ & $\begin{array}{c}\text { Ductility } \\
\text { index } \\
(\boldsymbol{\mu})\end{array}$ \\
\hline I-H-B & 4.97 & 5.06 & 6.22 & 26,98 & 5.33 \\
I-PP-B & 13.84 & 4.70 & 17.81 & 11.71 & 2.49 \\
I-CFRP-B & 11.25 & 4.24 & 14.06 & 16.01 & 3.78 \\
I-GFRP-B & 10.33 & 4.10 & 12.91 & 16.70 & 4.07 \\
& & & & & \\
U-H-B & 8.98 & 13.14 & 11.23 & 17.69 & 1.34 \\
U-PP-B & 12.38 & 13.60 & 15.48 & 19.86 & 1.46 \\
U-CFRP-B & 8.32 & 5.97 & 10.40 & 17.84 & 2.98 \\
U-GFRP-B & 9.91 & 5.84 & 12.39 & 17.74 & 3.04 \\
\hline
\end{tabular}




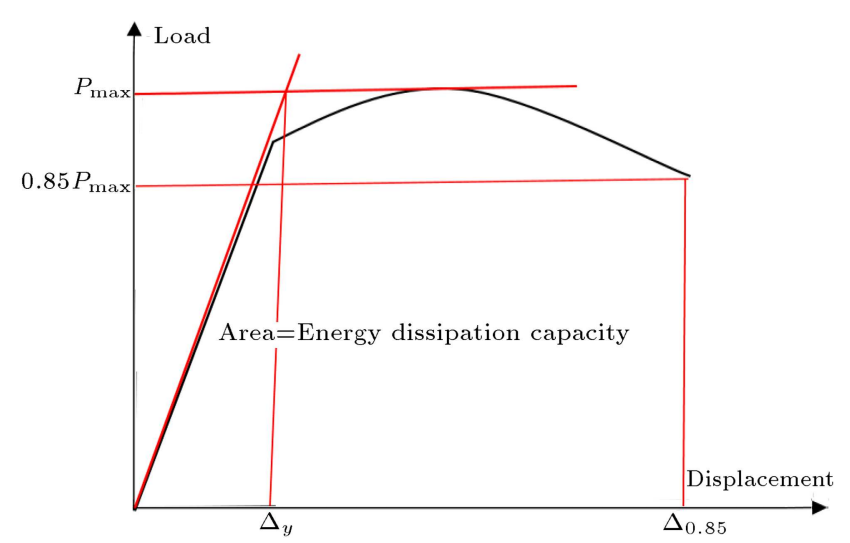

Figure 5. Calculation of the ultimate load, ductility index, and energy dissipation capacity.

U-H-B samples), respectively. Addition of the melted $\mathrm{PP}$ increased the ultimate load of the I- and U-section beams made of mild steel without making a change to their geometries. In other words, the moment of inertia remained the same. However, addition of the melted $\mathrm{PP}$ did not have a very positive effect on the ductility of the specimens. Further, addition of melted PP to the I-section beam reduced the ductility index, mainly because the I-section beam under the load could pass to the inelastic region under the bending moment of the beam. The melted PPs in it exhibited a relatively brittle behavior. Moreover, the addition of melted $\mathrm{PP}$ to the beam with a $\mathrm{U}$ cross-section increased the ductility index by $9 \%$ in contrast to the beam with an I cross-section. Although the melted PP I beam reduced the ability to displace in the web area, the U beam did not show this effect. It also caused the ultimate deflection value to increase by $12.3 \%$ in the $\mathrm{U}$ beam. The addition of melted PP increased the ductility index value under the bending moment since the $U$ beam had higher web thickness and lower web height than those of the I beam. The addition of GFRP bars with a higher elongation capacity in I and U beams caused ductile behavior than CFRP bars.

Figure 6 shows the load-midpoint displacement curves of $\mathrm{I}$ and $\mathrm{U}$ beams under bending moment. Addition of PP, CFRP, and GFRP melted to U beams rather than I beams made of mild steel significantly reduced displacement capacity. As expected, filling the empty spaces with PP, CFRP, and GFRP increased the rigidity while decreasing deformation capability. Changing the cross-section geometry had a positive effect on this reduction. The addition of $\mathrm{PP}$ to $\mathrm{U}$ beams increased the displacement capacity. Adding CFRP and GFRP to U beams did not have much effect on displacement capacity. Figure 6 shows that the addition of PP, CFRP, and GFRP bars melted in I-beams causes a more rigid behavior. The fact that the melted PP which replaces the voids in the Ibeams exhibits a brittle behavior caused the section
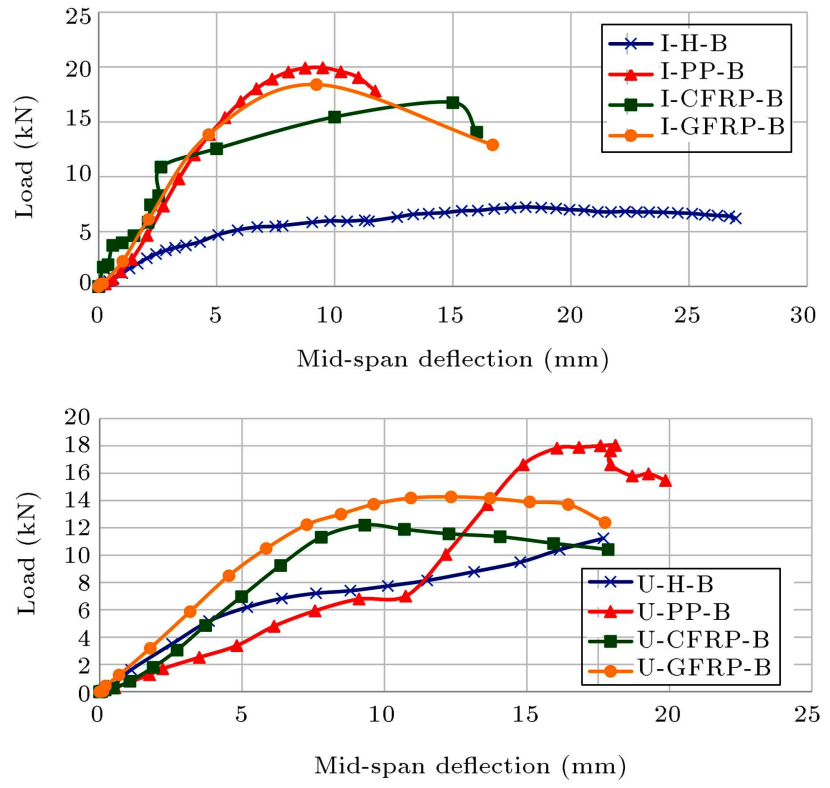

Figure 6. Load-deflection curves of the testes specimens under the bending moment.

to be more rigid. The melted PP and the I beam replacing the spaces reduced the displacement capacity, causing them to carry more loads. The hollow I-beam, on the other hand, displaced to a greater degree due to the voids in it; however, the load-carrying capacity decreased due to the crushing of these spaces under vertical load. Addition of a GFRP bar to the melted $\mathrm{PP}$ in I-beams had a more positive effect on the bending behavior than that of a CFRP bar. Greater elongation capacities of GFRP bar caused the beam to be more ductile. The addition of melted PP increased both resistance and displacement capacity in the U-beams. The fact that the gap area in the $U$ section is wider than the I section is the reason behind the occupation of greater space in the section by the melted PP.

Strain gauges placed in the beam mid-zone where the maximum moment was expected in a four-point bending test were recorded with deformation values. The stress-strain curves are presented in Figure 7. Maximum deformations have been achieved in hollow samples in I and U beams. The I beam, especially in CFRP-reinforced beams, exhibited greater deformation than the $\mathrm{U}$ beam. In the $\mathrm{U}$ beam, adding $\mathrm{PP}$ would increase the deformation capacity. While the melted PP increased the rigidity, CFRP and GFRP increased the deforming capability. However, the filling material and filling effect were of significance in such types of composites. The behaviors of GFRP and CFRP bars were related to the melted material, melting process, temperature, surface texture, etc. These parameters were mentioned in other studies, which were not taken into account in this study. Instead, the melting and/or extrusion method of the composite were observed in detail. 

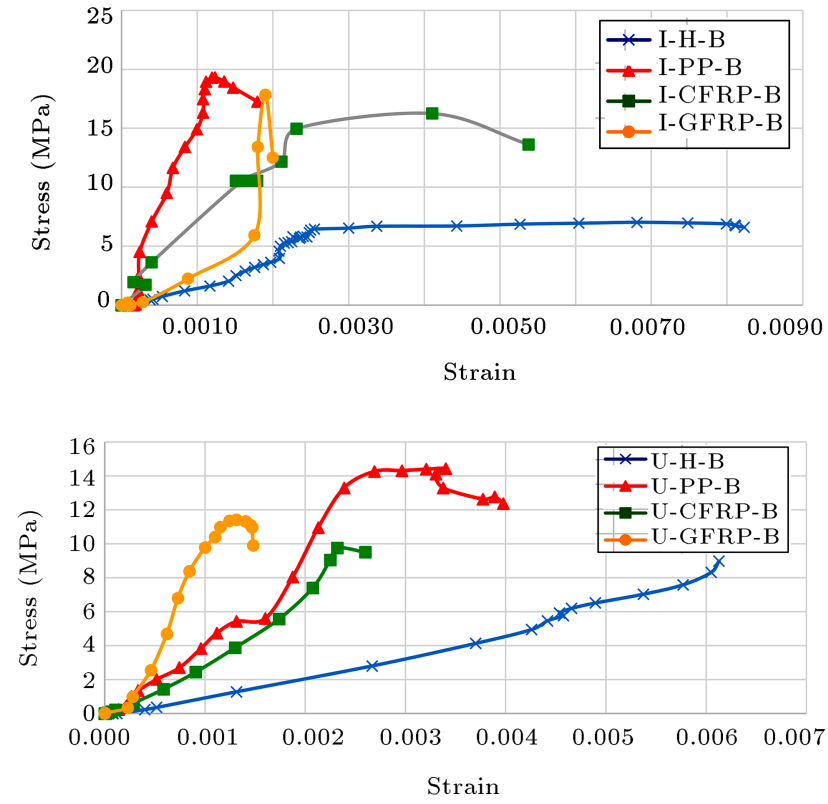

Figure 7. Stress-strain curves of the tested beams under the bending moment.

The energy dissipation capacities of the specimens were calculated in the area under the load-displacement curves drawn by the experimental data obtained in the four-point bending test. Figure 8 shows the energy dissipation curves of $\mathrm{I}$ and $\mathrm{U}$ beams under the bending moment. According to this figure, I-GFRP-B and U-PP-B beams had maximum energy dissipation capacities. Changing the cross-section significantly affected the energy dissipation capacity. The energy dissipation capacities of I-CFRP-B sample were $126 \%$, $40 \%$, and $132 \%$ more than those of I-H-B, I-PP-B, and I-CFRP-B specimens, respectively. Addition of melted PP and GFRP bars without changing the moment of inertia in the I section beam area made of mild steel could significantly increase the energy dissipation capacity. In addition to the PP melted in I-beams, the CFRP bars could increase their energy dissipation capacity owing to their high modulus of elasticity and elongation capacity. However, in addition to the melted $\mathrm{PP}$, adding CFRP bars did not have the same effect

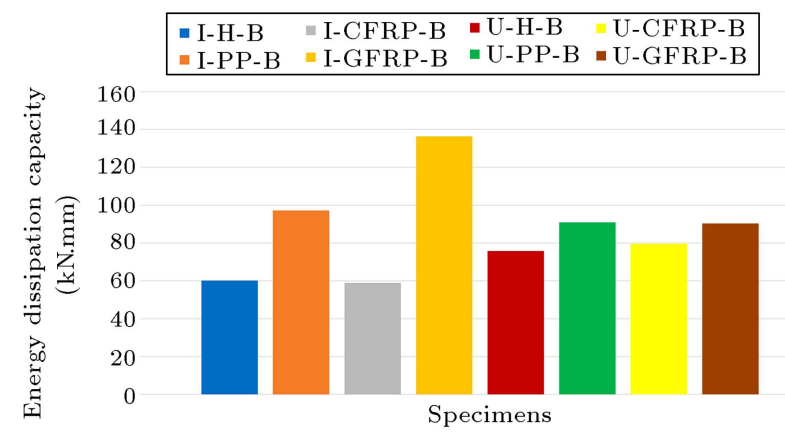

Figure 8. Energy dissipation capacity of the tested specimens under the bending moment. and even reduced its energy dissipation capacity due to its rigidity, compared to the reference sample I-HB. However, the energy dissipation capacities of the U-PP-B sample were $20 \%, 14 \%$, and $1 \%$ higher than those of U-H-B, U-CFRP-B, and U-GFRP-B samples, respectively. On the contrary, the addition of $\mathrm{PP}$ to $\mathrm{U}$ beams had a positive effect on the energy dissipation capacity. Moreover, incorporation of CFRP and GFRP bars, in addition to the melted PP, slightly increased the energy dissipation capacity. Of note, changing the cross-sectional area could reverse the effect of adding the mentioned material to the energy dissipation capacity. Even the energy dissipation capacities of hollow I and $U$ beams made of cold-formed steel are different from each other. Upon comparing the cross-sectional areas, the energy dissipation capacities of U-H-B and U-CFRP-B specimens were calculated as $26 \%$ and $35 \%$ higher than those of I-H-B and I-CFRP-B specimens, respectively, mainly due to their section properties, i.e., less amount of steel and melted material.

Figure 9 shows the pictures of beams that reach a failure mode after a four-point bending experiment. In the I-H-B sample under the bending moment, as the load increased, the initial deformation was observed between the left bracket of the profile and midpoint. At this point, with an increase in the loading, the deformation continued to the right region of the beam. Deformation was concentrated in the I-H-B profile close to the left support. With the increased loading in the I profile (I-PP-B) containing $\mathrm{PP}$ additive, there was no major deformation compared to the I-H-B beam first. In the following process, deformation occurred in the region close to the left support. However, when compared to the I-H-B beam, the deformation occurring in the left support was experimentally observed when $\mathrm{PP}$ had a positive effect in terms of both duration and size. Along with the increased loading in the ICFRP-B beam, a deformation of approximately $102 \mathrm{~cm}$ occurred near the right support. A slight collapse caused by this deformation was observed in the region between $100 \mathrm{~cm}$ and $150 \mathrm{~cm}$. With the increased loading in the I-GFRP-B beam, deformation occurred in the region between the left bearing and the midpoint, i.e., the point of approximately $55 \mathrm{~cm}$. The profile migrated from the point at which the deformation occurred intensely and an inward break was seen from that point. No deformation occurred in the area near the right support. In the U-H-B beam under the bending moment, the first deformation occurred in the central region of the beam. Upon increasing the bending moment, deformations were observed in the areas close to the bearing. In the U-PP-B beam, the first deformation took place on the right side of the beam. Then, with an increase in the first deformation, deformations were observed in the central region of the beam. As a result of the increased load, the 

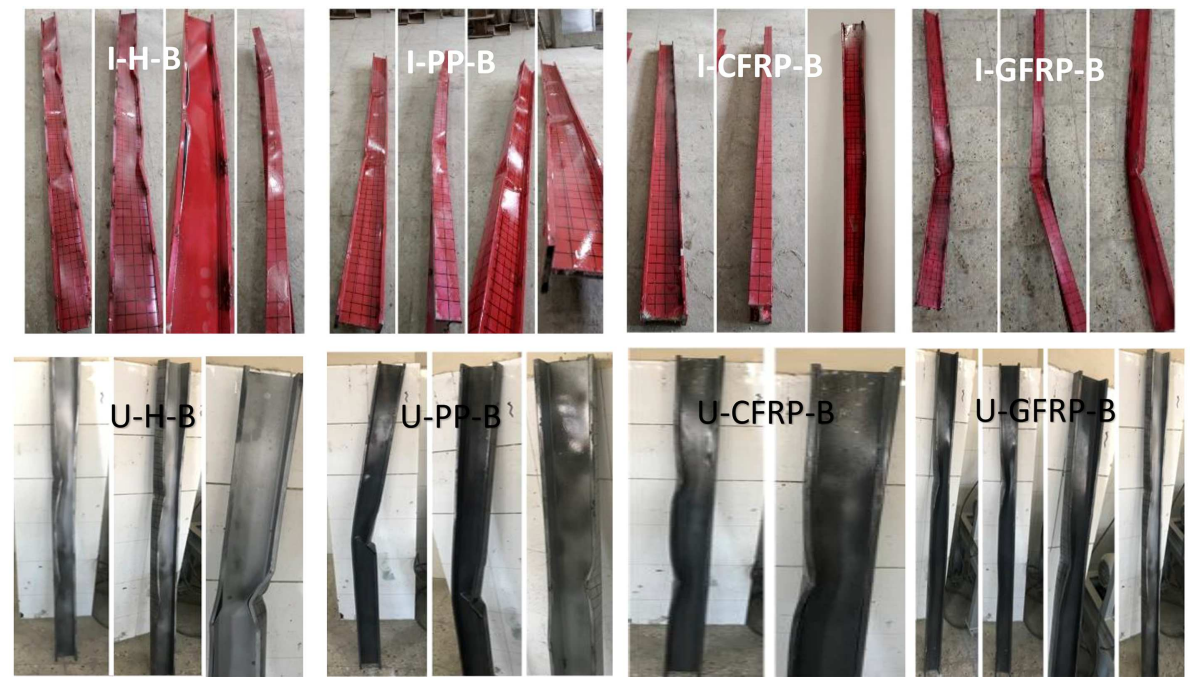

Figure 9. Tested specimens under the bending moment after failure.

sample collapsed. In the U-CFRP-B beam, as the load increased, the maximum deformation occurred in the areas close to the left support of the profile; however, no deformation was observed in the middle part of the profile. As the load increased in the U-GFRP$\mathrm{B}$ beam, the deformation occurred in the areas close to the support areas of the profile, where the greatest deformation occurred.

As expected, the main failure modes of the samples were observed as the local buckling with bending for four-point bending experiments. In particular, the symmetricity of the profile restrained the local buckling behavior, which is true for U-type models. Further, the inner composite material distribution at one-third of the beam span strikingly visualized the bending behavior above the mid-section as a result of inside heterogeneity.

\subsection{Shear behavior}

Building elements include building geometry, architectural conditions, loading situations, etc. according to different loads. Structural elements such as columns, beams, and floors are influenced by horizontal and vertical loading [36]. Feature beams are subjected to shear force, bending moment, and torsion moment loads, either separately or in combination. In some loading situations, shear force can be more significant than bending moment for the beam. In this section, the behavior of the I and U beams made of cold-formed steel with the loading mechanism created by changing the support conditions for researchers is examined. The values at these points were neglected because the displacement and displacement values in the region between the two supports in the shear test arrangement would be close to zero according to the researchers' predictions. Although LVDT was placed in this region for control purposes, these values were not used in the drawn curves. Displacement and deformations were measured in the free end region. The shear force was calculated based on the maximum force in the free-end in the shear force diagram.

The experiment was completed when the shear force value reached $85 \%$ in beams with maximum load in the free end region. The shear force value at this point is recorded as the ultimate load. Table 4 shows the test results of beams under shear force. Addition

Table 4. Test results of the tested beams under the shear force.

\begin{tabular}{lccccc}
\hline Specimen & $\begin{array}{c}\text { Load } \\
\text { at yield } \\
(\mathbf{k N})\end{array}$ & $\begin{array}{c}\text { Deflection } \\
\text { at yield load } \\
\mathbf{( \mathbf { m m } )}\end{array}$ & $\begin{array}{c}\text { Ultimate } \\
\mathbf{l o a d} \\
\mathbf{( k N )}\end{array}$ & $\begin{array}{c}\text { Ultimate } \\
\text { deflection } \\
\mathbf{( m m})\end{array}$ & $\begin{array}{c}\text { Ductility } \\
\text { index } \\
(\boldsymbol{\mu})\end{array}$ \\
\hline I-H-S & 7.28 & 6.90 & 9.10 & 9.00 & 1.30 \\
I-PP-S & 23.16 & 2.47 & 28.94 & 7.64 & 3.10 \\
I-CFRP-S & 9.38 & 6.27 & 11.73 & 16.65 & 2.66 \\
I-GFRP-S & 13.42 & 2.18 & 16.77 & 8.46 & 3.88 \\
& & & & & \\
U-H-S & 10.05 & 4.05 & 12.56 & 21.49 & 5.31 \\
U-PP-S & 20.49 & 1.98 & 25.61 & 15.95 & 8.06 \\
U-CFRP-S & 10.8 & 5.60 & 13.50 & 7.14 & 1.28 \\
U-GFRP-S & 14.84 & 4.80 & 18.55 & 8.45 & 1.76 \\
\hline
\end{tabular}


of PP to beams under shear force caused an increase in the ultimate load level. The ultimate loads of I-PP-S and U-PP-S beams were $218 \%$ and $104 \%$ higher than those of the reference samples (compared to I-H-S and U-H-S samples), respectively. Moreover, compared to the addition of the CFRP bar, addition of the GFRP bar to the melted PP in both I and U beams increased the ultimate load to a value more than that of the reference specimen. However, the FRP bar inclusion decreased the ultimate load for both CFRP and GFRP bars. Furthermore, the relevant varying ultimate load increases can be related to the number of bars used within the I and U sections. Similar to the fourpoint bending test, changing the cross-sectional area in shear tests could significantly affect the load at yield and final load values. Addition of GFRP in I beams under the shear force PP addition in U beams had the most positive effect on the ductility index. Addition of GFRP with both PP and CFRP to the I beams could increase the ductility index value only by adding $\mathrm{PP}$ in $\mathrm{U}$ beams. The loss of continuity and adherence through bars increased the ultimate load and deformation capability. The addition of CFRP to the I beams significantly increased the displacement capacity of the beam in the free-end region. In $U$ beams, hollow beams reached the highest displacement capacity.

Shear load-shear displacement plots drawn by calculating the free-end deformations are shown in Figure 10. The load displacement curve linearly increased the hollow I beam specimen. The loaddisplacement curves of other I section beams also increased nonlinearly. The addition of PP and CFRP to the I-beams resulted in more rigid and ductile behavior,
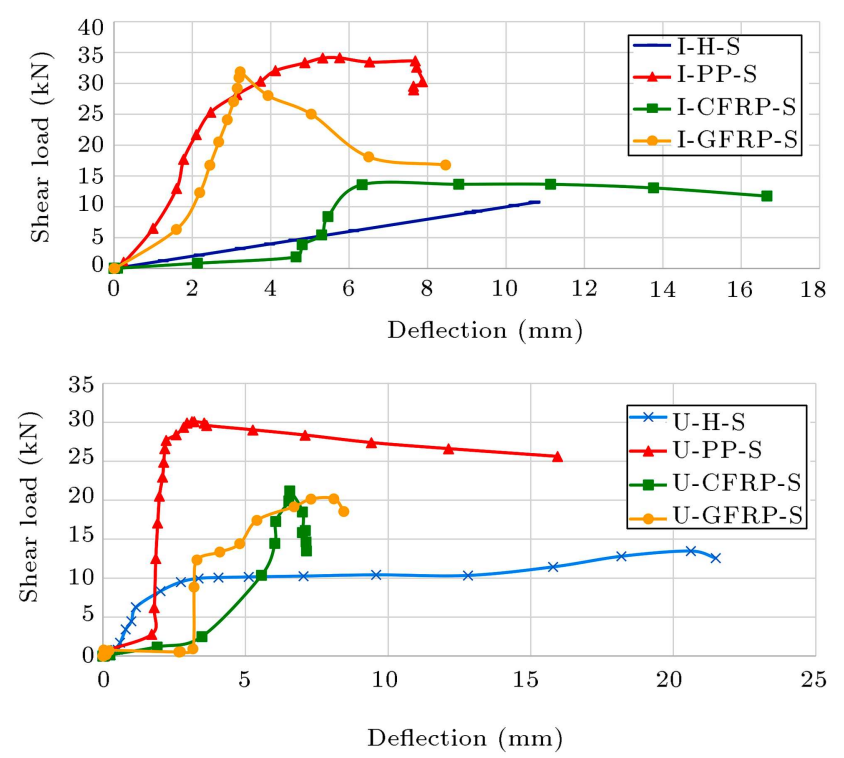

Figure 10. Load-deflection curves of the tested beams under shear force. respectively. Adding $\mathrm{PP}$ to $\mathrm{U}$ beams had a significant effect on strength. However, addition of CFRP and GFRP to U beams reduced both strength and ductility. Changing the geometry of the cross-section led to the alteration of the shear load-shear displacement curves. It was shown that similar to the four-point bending test, the characteristics of the beams such as resistance, displacement, ductility, and energy dissipation could be altered without changing the cross-section. The resistance of beams under bending differed from that under shear. Therefore, changing the loading type had an effect on the characteristic properties of beams. In the I beam, the ultimate resistance of CFRP- and GFRP-reinforced beams under bending was higher than that under shear and the ultimate resistance of hollow and PP reinforced beams was lower. In the $\mathrm{U}$ beams, the ultimate resistance of the beams under bending was lower than that under shear, except for the U-GFRP specimen. Therefore, both hollow and doped I and U beams made of mild steel performed better under shear force.

Deformations were recorded with strain gauges attached to the free-end region of beams under shear force. In Figure 11, stress-strain curves of beams under shear force are given. The hollow section deformation capacity can be seen as going on a graph in Figures 10 and 11. As seen earlier, the melted PP within the hollow sections improved not only the deformation capability, but also the maximum loading capacity of the member, which could be justified by the sectional property change, as expected. Furthermore, the adherence loss between hollow section and PP using bars decreased the increasing deformation and rigidity of the
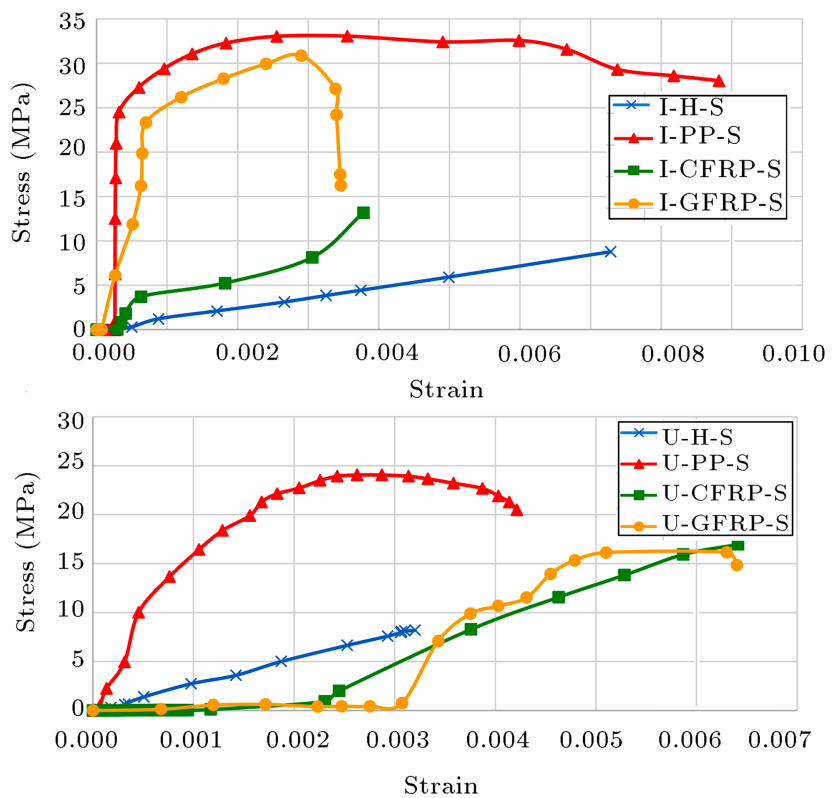

Figure 11. Stress-strain curves of the tested beams under shear force. 


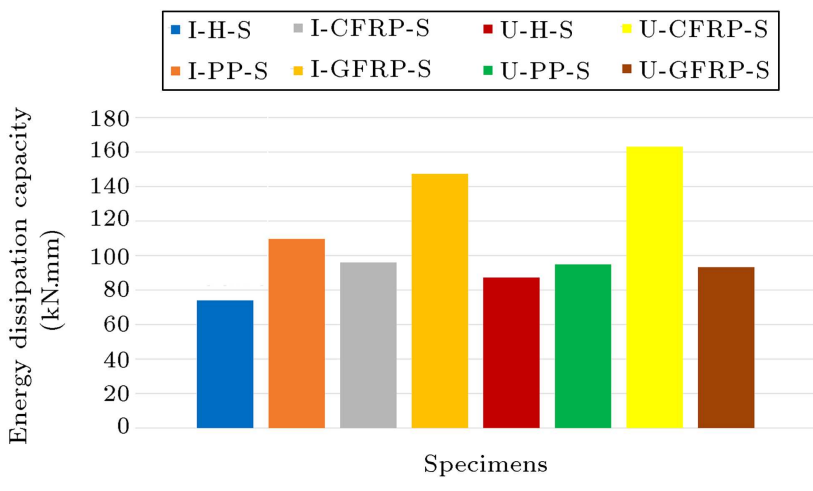

Figure 12. Energy dissipation capacity of the tested beams under shear force.

composite. However, this mentioned phenomenon must be investigated in detail for future research.

Energy dissipation capacity graphs of I and U beams were drawn from the area under the shear force-shear displacement curves (Figure 12). I-PP-S, ICFRP-S, and I-GFRP specimens in I beams increased by $48 \%, 30 \%$, and $99 \%$, respectively, compared to the reference specimen, I-H-S. In U beams, U-PP-S, UCFRP-S, and U-GFRP specimens in beams increased by $8 \%, 87 \%$, and $7 \%$, respectively, compared to U$\mathrm{H}-\mathrm{S}$ reference specimen. However, the improvement of the energy dissipation capabilities did not exactly demonstrate the flexibility, enough. The bars and the melted PP improved the maximum load capacity within the limitation of adherence between the hollow steel section and the PP material. The adherence importance for this phenomenon increased with the bar application. Furthermore, the inner surface area of the hollow section was another affecting parameter of adherence which appeared between the I and U type profiles.

As the section geometry affected the energy dissipation capacity, changing the loading style also influenced the energy dissipation capacity. Upon a comparison between Figure 8 and Figure 12, the energy dissipation capacities of the I beam under bending were lower than those under shear. The I and U beams made of mild steel exhibited a better energy dissipation performance under shear. As expected, the free space in the section yielded a higher deformation capability according to the filled section. However, the area under stress-strain could not be explained without considering maximum load. The energy dissipation capacities of the I-PP-S and U-PP-S beams were $13 \%$ and $4 \%$, respectively, compared to the I-PP-B and UPP-B beams.

Figure 13 shows the images of those beams that had reached the failure mode, as demonstrated by the shear test. Upon increase in loading on the I-H-S beam under shear force, collapse occurred at the points of $50 \mathrm{~cm}$ and $100 \mathrm{~cm}$ in the right support. No deformation occurred at the left support and end point (between $100 \mathrm{~cm}$ and $150 \mathrm{~cm}$ ). The increased loading on the I-PP-S beam in the shear test did not cause major deformation at the $50 \mathrm{~cm}$ and $100 \mathrm{~cm}$ points where the LVDTs were located, and no collapse occurred at these points when compared to the I-H-S beam. In this sample where relatively large deformation did not occur at yielding, opening in the profile occurred after yielding. Increased loading on the I-CFRP-S beam caused deformation at approximately $76 \mathrm{~cm}$ away from the right bearing. In the I-GFRP-S beam, a slight collapse occurred at approximately $50 \mathrm{~cm}$ and $100 \mathrm{~cm}$
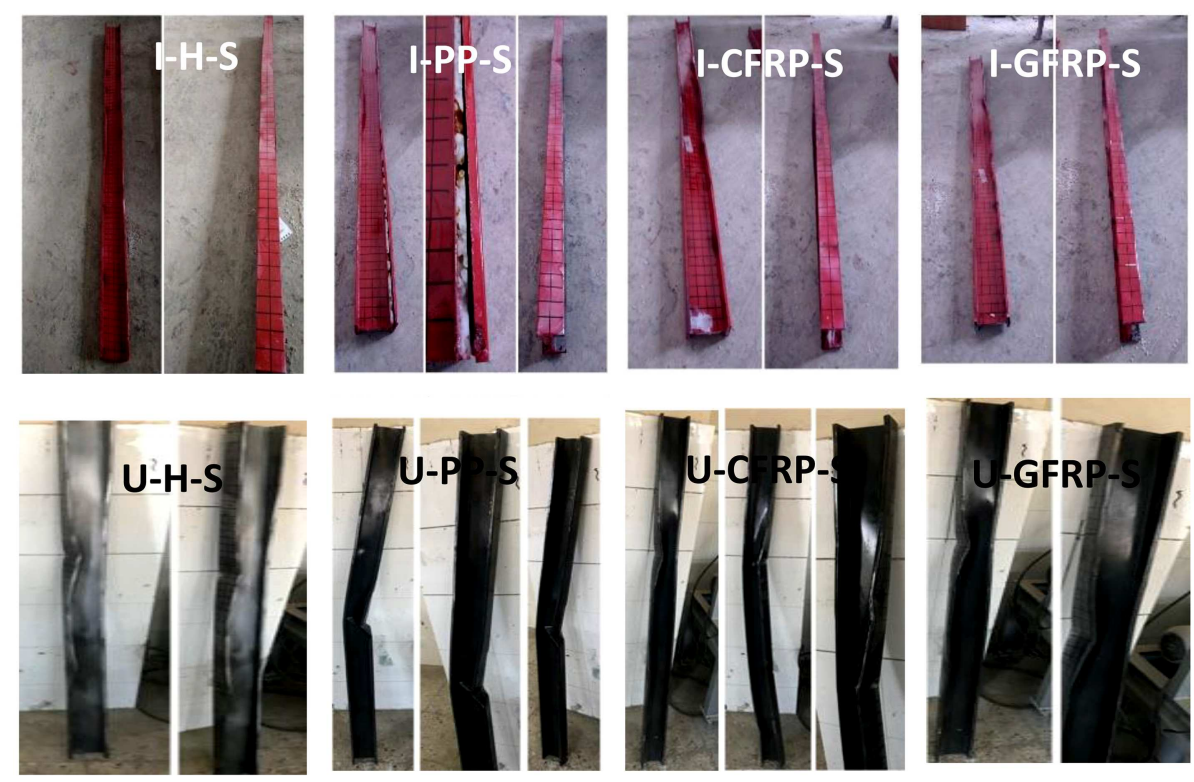

Figure 13. Tested specimens under shear force after failure. 
away from the right bracket after increased loading, and no major deformation was observed.

In the U-H-S beam, as the load increased in the shear test, deformation was observed in the middle point of the profile; however, it remained at a very low level in the areas close to the left support of the profile. In the U-PP-S beam under shear, deformation is observed in the middle point of the profile as the load increased and deformation increased as the load increased in the free-end region. Upon increase in loading, the slump occurred in the beam. As the load increased in the shear test in the U-CFRP-S beam, the highest deformation was observed in the middle point of the profile. Deformation occurring at the other support end of the profile is less than that in the left support area of the profile. In the U-GFRP-S beam, as the load increased, maximum deformation occurred in the regions close to the middle region of the profile and no deformation at the end of the profile was observed.

The enhancement of hollow section profiles with PP and CFRP/GFRP is the main striking point of this work. Furthermore, the waste PP is another point of view to achieve a clean environmental perspective. Nonetheless, the filling ability of PP is mainly a function of designed experimental melting setup which must be upgraded through extensive researches. The used PP particles are discrete and possibly, after the melting process, the formation of melted PP has voids and non-uniform sectional properties. Thus, the uniformity of the inner section can be variable and can present fluctuating responses. No consolidating technique was used throughout this study and this paradigm was designed the same for all. Therefore, the maximum and ultimate load capacity of the cold-formed hollow sections increased to higher levels by using the melted PP as filling material. The CFRP and GFRP bars are planned to be used as reinforcing members for the profiles. The reinforcing CFRP/GFRP has a compact section, but the surfaces of the bars are smooth and the adhesion between the PP and the bars and cold-formed profile is limited. Withal, continuity, and compact properties of the bars enhanced the shear and bending behavior of the samples. The elongation capability of the GFRP is about two times greater than the CFRP. This phenomenon can be seen in the energy dissipation capacity for bending and shear tests of both profiles. The cross-sectional properties of U-type profiles can hardly be considered as the main result of less enhanced energy dissipation, compared to the I type profiles. The sectional energy dissipation capability is also related to the moment of inertia for the sections, and this phenomenon can be seen in the results, as expected. The filled sectional properties attenuated the deflection capability. Moreover, the U type profiles enhanced the rigidity by about two times, while this enhancement was only about 1.2 for I type profiles. When the hollow and filled samples were compared, the existence of PP throughout the member escalated the shear behavior. As expected, the main failure modes of the samples were observed as local buckling for both bending and shear type experiments. Such properties as withal, twisting, and lateral torsional buckling were seen for the melted PP filled and/or CFRP and GFRP samples. In particular, the symmetricity of the profile hampered the torsional behavior, which was strikingly true for $\mathrm{U}$ type models with twisting.

\section{Conclusion}

The present study aimed to experimentally evaluate the bending and shear behaviors of the beams with I and U cross-sectional areas made of cold-formed steel. The effect of the joints on the characteristic values for the beams was evaluated by adding Polypropylene (PP), Carbon Fiber-Reinforced Polymer (CFRP), and Glass Fiber Reinforced-Polymer (GFRP) bars to the hollow I and U beams. As a result of the experimental study, the following conclusions were drawn:

- Changing the cross-sectional areas in the I and U beams under bending moment could affect the load at yielding, ultimate strength, displacement values corresponding to these loads, ductility, and energy dissipation capacity. In general, the addition of melted PP had a positive effect on the behavior of beams. The maximum energy dissipation capacity was achieved by adding GFRP bars with PP melted in the I beam under bending. Further, the addition of PP and GFRP to the U beams under bending could significantly increase the maximum energy dissipation capacity, compared to the reference sample;

- In the beams under the bending moment, collapses generally occurred in the central zone of the beam. In both I and $U$ beams made of cold-formed steel under shear force, changing the cross-section had a significant effect on the displacement, ductility, and energy dissipation capacity. Both I and U beams made of mild steel, both reinforced and doped, outperformed under shear force;

- In the four-point bending test, the highest ultimate load value for IPE 100 and UPE 100 groups was achieved in I-PP-B and U-PP-B samples, respectively. However, the ductility index value was maximum in I-H-B and U-GFRP-B samples, respectively;

- The ultimate load value for the I-PP-S and U-PP-S samples was the highest in the IPE 100 and UPE 100 groups. The maximum ductility index was obtained from I-GFRP-S and U-PP-S samples. The shear strength of the samples with I and U crosssections was higher than the flexural strength of 
such samples. Adding molten PP to the samples increased both shear and flexural strengths in all groups;

- Cold-formed light steel composites have been significantly applied in the construction sector. This study presented an innovative approach to waste polymer assessment with the cold-formed steel hollow sections. Yet, to complete this process, more detailed works are required for a wide variety of profiles, joints, etc.

\section{Acknowledgment}

The research is part of the Ataturk University Project No: FYL-2019-7353 and FYL-2019-7354. The authors would like to thank Ataturk University for funding the project.

\section{References}

1. Ren, C., Dai, L., Huang, Y., et al. "Experimental investigation of post-fire mechanical properties of Q235 cold-formed steel", Thin-Walled Structures, 150, p. 106651 (2020).

2. York, C.B. and Pedreschi, R. "The influence of geometry on the strength of shear wall panels in light steel construction", Construction and Building Materials, 14, pp. 277-285 (2000).

3. Nie, B., Xu, S., Zhang, Z., et al. "Experimental investigation on corroded cold-formed steel beamcolumns under compression and major axis bending", Journal of Constructional Steel Research, 169, p. 106026 (2020).

4. Davies, J.M. "Recent research advances in cold-formed steel structures", Journal of Constructional Steel Research, 55, pp. 267-288 (2000).

5. Gu, F., Guo, J., Zhang, W., et al. "From waste plastics to industrial raw materials: a life cycle assessment of mechanical plastic recycling practice based on a realworld case study", Science of Total Environ, 601, pp. 1192-1207 (2017).

6. Ragaert, K., Delva, L., and Geem, K.V. "Mechanical and chemical recycling of solid plastic waste", Waste Manage, 69, pp. 24-58 (2017).

7. Barrera, G.M., Lopez, M.M., Diaz, J.J.C., et al. "Waste polymers and gamma radiation on the mechanical improvement of polymer mortars: Experimental and calculated results", Case Studies in Construction Materials, 11, p. e00273 (2019).

8. Biron, M. "Recycling: The First Source of Renewable Plastics", in Industrial Applications of Renewable Plastics, Environmental, Technological, and Economic Advances, Elsevier, United Kingdom, 632 pages, ISBN: 978-0-3234-806-59 (2017).

9. Achilias, D.S., Roupakias, C., Megalokonomos, P., et al. "Chemical recycling of plastic wastes made from polyethylene (LDPE and HDPE) and polypropylene (PP)", Journal of Hazardous Materials, 149, pp. 536$542(2007)$.

10. Al-Maadeed, M.A., Shabana, Y.M., and Khanam, P.N. "Processing, characterization and modeling of recycled polypropylene/glass fibre/wood flour composites", Materials and Design, 58, pp. 374-380 (2014).

11. Maali, M., Sagiroglu, M., and Solak, M.S. "Experimental behavior of screwed beam-to-column connections in cold-formed steel frames", Arabian Journal of Geosciences, 11(9), p. 205 (2018).

12. Mohamed, N., Farghaly, A.S., Benmokrane, B., and Neale, K.W. "Experimental investigation of concrete shear walls reinforced with glass fiber-reinforced bars under lateral cyclic loading", J. Compos. Constr., 18(3), A4014001, pp. 1-11 (2014).

13. Kassem, C., Farghaly, A.S., and Benmokrane, B. "Evaluation of flexural behavior and serviceability performance of concrete beams reinforced with FRP Bars", Journal of Composites for Construction, 15(5), pp. 682-695 (2011).

14. Tobbi, H., Farghaly, A.S., and Benmokrane, B. "Concrete columns reinforced longitudinally and transversally with glass fiber-reinforced polymer bars", $A C I$ Struct. J., 109(4), pp. 551-558 (2012).

15. Maali, M., Aydın, A.C., Showkati, H., et al. "The effect of longitudinal imperfections on thin-walled conical shells", Journal of Building Engineering, 20, pp. 424441 (2018).

16. Sağıroğlu, M., Maali, M., Kılıç, M., et al. "A novel approach for bolted T-stub connections", International Journal of Steel Structures, 18(3), pp. 891-909 (2018).

17. Vojdan, B.M. and Aghayari, R. "Investigating the seismic behavior of RC shear walls with openings strengthened with FRP sheets using different schemes", Scientia Iranica, 24(4), pp. 1855-1865 (2017).

18. Vecchio, F., Haro, P.O., Bucci, F., et al. "Behavior of repaired cyclically loaded shear walls", ACI Structural Journal, 99(3), pp. 27-334 (2002).

19. Taghdi, M., Bruneau, M., and Saatcioglu, M. "Seismic retrofitting of low-rise masonry and concrete walls using steel strips", Journal of Structural Engineering, 126(9), pp. 1017-1025 (2000).

20. Maali, M., Kılıç, M., Yaman, Z., et al. "Buckling and post-buckling behavior of various dented cylindrical shells using CFRP strips subjected to uniform external pressure: Comparison of theoretical and experimental data", Thin-Walled Structures, 137, pp. 29-39 (2019).

21. Altin, S., Anil, Ö., Kopraman, Y., et al. "Hysteretic behavior of RC shear walls strengthened with CFRP strips", Composites: Part B, 44, pp. 321-329 (2013).

22. Dan, D. "Experimental tests on seismically damaged composite steel concrete walls retrofitted with CFRP composites", Engineering Structures, 45, pp. 338-348 (2012). 
23. Meftah, S.A., Yeghnem, R., Tounsi, A., et al. "Seismic behavior of RC coupled shear walls repaired with CFRP laminates having variable fibers spacing", Construction and Building Materials, 21(8), pp. 1661-1671 (2017).

24. Delnavaz, A. and Hamidnia, M. "Analytical investigation on shape configuration of CFRP strips on lateral loading capacity of strengthened RC shear wall", Structural Concrete, 17(6), pp. 1059-1070 (2016).

25. Quazi, S., Michel, L., and Ferrier, E. "Seismic behavior of RC short shear wall strengthened with externally bonded CFRP strips", Composite Structures, 211, pp. 390-400 (2019).

26. Arafa, A., Farghaly, A.S., and Benmokrane, B. "Effect of web reinforcement on the seismic response of concrete squat walls reinforced with glass-FRP bars", Engineering Structures, 174, pp. 712-723 (2018).

27. Al-Nini, A., Nikbakht, E., Syamsir, A., Shafiq, N., Mohammed, B.S., Al-Fakih, A., and Amran, Y.H. "Flexural behavior of double-skin steel tube beams filled with fiber-reinforced cementitious composite and strengthened with CFRP sheets", Materials, 13(14), p. 3064 (2020).

28. Zhao, X.L. and Zhang, L. "State-of-the-art review on FRP strengthened steel structures", Engineering Structures, 29(8), pp. 1808-1823 (2007).

29. Yu, T., Wong, Y.L., Teng, J.G., et al. "Flexural behavior of hybrid FRP-concrete-steel double-skin tubular members", Journal of Composites for Construction, 10(5), pp. 443-452 (2006).

30. Idris, Y. and Ozbakkaloglu, T. "Flexural behavior of hybrid double-skin-tubular beams", In Advanced Materials Research, 838, pp. 525-529 (2014).

31. Wang, Q.L. and Shao, Y.B. "Flexural performance of circular concrete filled CFRP-steel tubes", Advanced Steel Construction, 11(2), pp. 127-149 (2015).

32. Maali, M., Kılıç, M., Bayrak, B., et al. "Behavior of polypropylene filled cold formed steel profiles-Part A: Bending shear", Civil Engineering Beyond Limits, 1, pp. 1-6 (2020).

33. Kılıç, M., Maali, M., Bayrak, B., et al. "Behavior of polypropylene filled cold formed steel profiles-Part B: Torsion", Civil Engineering Beyond Limits, 1, pp. 7-11 (2020).

34. EN 10365 "Hot rolled steel channels, I and H sectionsdimensions and masses", Ankara, Turkey (2007).

35. Nikbakht, E., Al-Fakih, A., Hui, C.C., et al. "An experimental investigation on the shear and flexural behavior of steel reinforced HPSCC beams", In Structures, 19, pp. 286-295 (2019).

36. Aydın, A.C. and Bayrak, B. "The torsional behavior of reinforced self-compacting concrete beams", Advances in Concrete Construction, 8(3), pp. 187-198 (2019).

\section{Biographies}

Abdulkadir Cüneyt Aydın received his BSc degree in Civil Engineering from Karadeniz Technical University, Turkey in 1996, and MSc and PhD degrees in Structural Engineering in 1998 and 2004 from Atatürk University, respectively. He is currently a Professor at Atatürk University. His research interests include the structural engineering, steel structures, composite materials, retrofitting and repair of structure, and masonry buildings.

Barış Bayrak received his BSc degree in Civil Engineering from Atatürk University, Turkey in 2012 and an MSc degree in Structural Engineering in 2015 from Atatürk University. He is currently a PhD student at Atatürk University.

Mahyar Maali was born in Iran in 1985. He received his BSc degree in Civil Engineering in 2008 and $\mathrm{MSc}$ and $\mathrm{PhD}$ degrees in Structural Engineering from Maragheh Azad University (2011) and Atatürk University (2016), respectively. His research interests include the structural engineering and steel structures. He is currently a staff member in Erzurum Technical University.

Elif Mete was born in Trabzon, Turkey. She received her BSc and MSc degrees in Civil Engineering and Steel Structure from Erzincan Binali Yıldırım University in 2017 and 2020, respectively. Her research interests include reinforcement concrete structures, steel structure, composite materials, and waste management. She is currently a PhD student at Atatürk University.

Kübra Çebi was born in Trabzon in 1995. She received her BSc and MSc degrees in Civil Engineering and Steel Structure from Erzincan Binali Yıldırım University in 2017 and 2020, respectively. Her current research interests include solid waste, plastic waste, polymer waste, steel structure, and composite materials. She has published two international papers about composite materials.

Mahmut Kılıç received his BSc degree in Civil Engineering and Mechanical Engineering from Atatürk University, Turkey in 2009 and 2010, respectively. He received his $\mathrm{MSc}$ and $\mathrm{PhD}$ degrees in Structural Engineering in 2014 and 2017 from Atatürk University, respectively. He is currently a staff member at Atatürk University. 